\title{
An Electrochemical Method for the Determination of Trace Mercury (II) by Formation of Complexes With Indigo Carmine Food Dye and Its Analytical Application
}

\author{
Roger Seiny N'Dri ${ }^{1,2}$, Mariame Coulibaly ${ }^{1, *}$, Alfred N'Guessan Yao ${ }^{1}$, Drissa Bamba ${ }^{1}$, \\ Elogne Guessan Zoro ${ }^{1}$ \\ ${ }^{1}$ Laboratoire des Sciences Physiques Fondamentales et Appliquées, Ecole Normale Supérieure \\ 08 BP 10 Abidjan, Côte d'Ivoire \\ ${ }^{2}$ Laboratoire de Physique de la matière condensée et technologie, Université Félix Houphouët Boigny \\ de Cocody, 01 BP V 3, Abidjan, Côte d'Ivoire \\ *E-mail: mamecoul2002@yahoo.fr
}

doi: $10.20964 / 2016.06 .61$

Received: 25 February 2016 / Accepted: 20 March 2016 / Published: 1 May 2016

The interaction between mercury and indigo carmine (IC) was studied using differential pulse voltammetry (DPV) technique. In aqueous medium, a decrease of oxidation current of IC was observed due to the formation of a complex of IC with $\mathrm{Hg}$ (II). The reaction of complexation was monitored and some important parameters such as metal concentration, $\mathrm{pH}$, temperature and time of reaction were investigated and optimized. Under the optimum conditions, the linear range of the calibration curve, obtaining by representing the IC oxidation current as function of the $\mathrm{Hg}$ (II) concentration (pH 10), was from $25 \mathrm{nM}$ (5 ppb) to $200 \mathrm{nM}$ (40 ppb) $\mathrm{Hg}$ (II) and the detection limit was $7.5 \mathrm{nM}(1.5 \mathrm{ppb})$. The results show that this new method enable simple, a sensitive and rapid determination of mercury.

Keywords: Differential pulse voltammetry; carbon paste electrode; mercury; indigo carmine

\section{FULL TEXT}

(C) 2016 The Authors. Published by ESG (www.electrochemsci.org). This article is an open access article distributed under the terms and conditions of the Creative Commons Attribution license (http://creativecommons.org/licenses/by/4.0/). 